\title{
A Review on: Job Portal- A Web Application for Distributed Clients
}

\author{
Pooja T. Killewale ${ }^{1}$, Prof A.R. Mune $^{2}$ \\ ME. Student, CSE Dept DRGITR, AMT ${ }^{1}$ \\ Asst. Professor CSE Dept, DRGITR, AMT ${ }^{2}$
}

\begin{abstract}
This research aims to develop a job web portal for the students in the Faculty of Computer Science and Information Technology The main aims of this portal are to connect to the industries and acts as an online recruitment to support the students to find the right IT job after graduation. Furthermore, this system enhances the understanding concept and importance of the job portal for students in the universities. A survey was conducted to identify the students' problems with the existing portal of the faculty and to gather their requirements which can be incorporated in to the portal to be developed.
\end{abstract}

Keywords: Job Advertisement, job hunting, job portal, job posting, job search, content management system, and webbased system.

\section{INTRODUCTION}

Unemployment is one of the serious social issues faced by both developing and developed and countries. For example, in Europe the rate of unemployment has been increasing rapidly since the 1970's.Dorn and Naz Mentioned that one of the reasons for this problem is the unfair distribution or lack of information on job opportunities so people are unable to now the new job vacancies. It means that there are some jobs available, but jobseekers do not have access to that information. An efficient search of the internet might help to jobseekers in their job hunt. There are some web portals that provide an efficient way to search the web for online information on job vacancies for jobseekers.

Today, the internet has changed many aspects of our life ,such as the way we look for jobs If one person wants to find a new job, he/she can submit a resume using word processing software like Microsoft Office Word, open a web browser to send the resume and receive an e-mail. Online recruitment has become the standard method for employers and jobseekers to meet their respective objectives.

\section{IMPLEMENTATION}

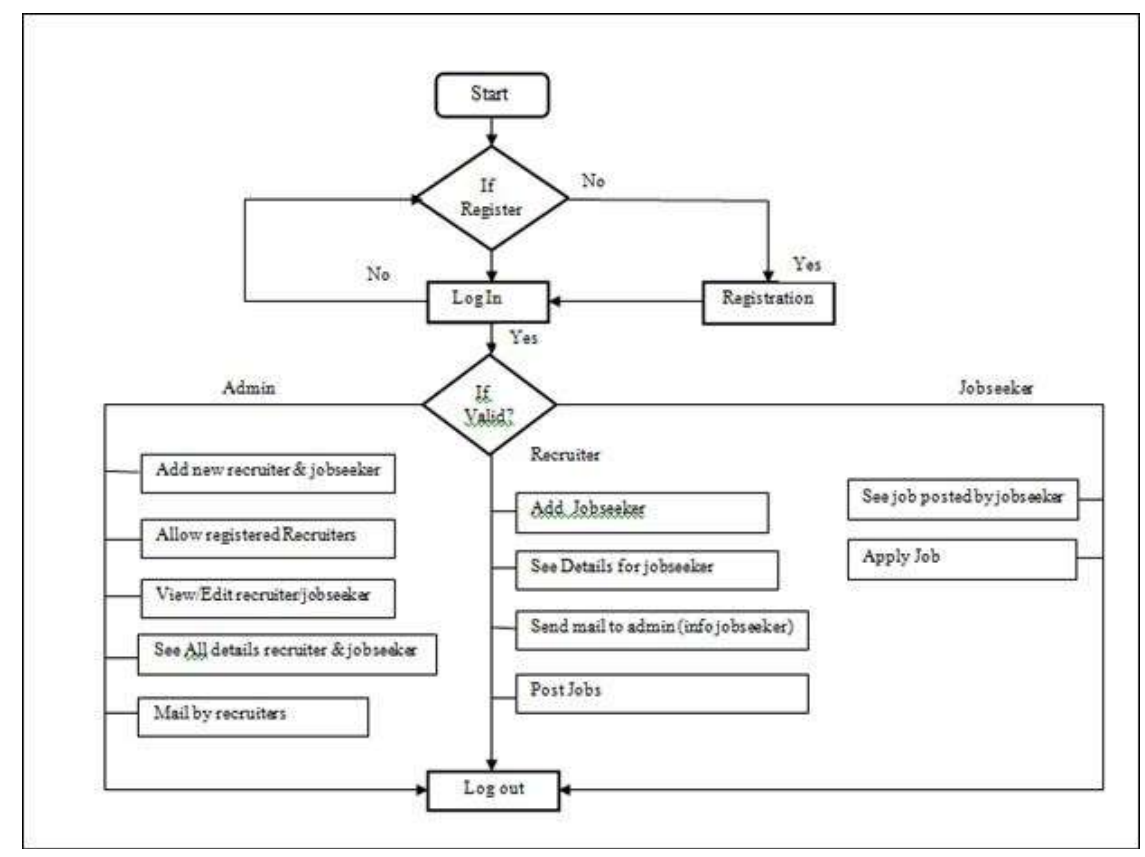


Algorithm :

Admin :

Step 1 :- Start

Step 2 :- Enter username and password.

Step 3 :- Check admin is authorized or not from Admin table database.

Step 4 :-If authorized than get all its rights. And go to next step, if wrong then go to step 3.

Step 5 :- Admin can confirm or deny Recruiter and view Recruiter detail.

Step 6 :- Admin can manage jobseeker detail.

Step 7 :- Admin can view reports.

Step 8 :- If unauthorized than set message "Unauthorized user."

Step 9 :- logout

Step 10:- Stop.

\section{Recruiter:}

Step 1:- Start

Step 2:- Enter username and password.

Step 3:- Check Recruiter is authorized or not from recruiter table database.

Step 4:- If authorized than get all its rights. And go to next step, if wrong then go to step4.

Step 5:- Recruiter can post a job.

Step 6:- Recruiter can view jobseeker detail.

Step 7:- If unauthorized than set message "Unauthorized user."

Step 8:- Logout

Step 10:-Stop

Jobseeker:

Step 1:-Start

Step 2:-Fill Registration form and upload resume.

Step 3:-Enter username and password.

Step 4:-Check Jobseeker is authorized or not from Jobseeker_table database.

Step 5:-If authorized than get all its rights. And go to next step, if wrong then gotostep4.

Step 6:-Jobseeker view company detail.

Step 7:-Jobseeker view company requirement and give feedback

Step 8:-Job seeker apply for the job.

Step 9:-If unauthorized than set message "Unauthorized user."

Step 10:-Logout

Step 11:-Stop

\section{III.LITERATURE REVIEW}

A. Job Procurement: Old and New Ways Job seeking usually involves different ways to look for jobs such as through personal contacts, direct telephone calls to employers, job agency office, scanning online job listings, etc. [3]. Before the Internet, became widely uses as a method of seeking jobs, jobseekers spent a lots of time using various methods to look for job openings. Today, jobseekers use online methods which are very convenient and save a lot of time. Galanaki [5] lists the following methods to be the traditional (old) ways for recruitment:

$\square \square$ Employment recruitment agencies

Job fairs

Advertising in the mass media such as newspapers

Advertisement in television and radio

Management Consultants

Existing employee contacts

Schools colleges oruniversities students services department

Workers or professional referrals

These old job seeking methods are too slow, stressful, challenging and also lack quality [6]. In addition, the applicants have to consider the cost and the amount of time toget the information they need, and other preparations they have to make. Finding all available job vacancies is a main step at in the job-seeking process. The Internet is now a powerful tool that jobseekers can use. Today, there are many sites that advertise job positions to be filled by people with certain skills in various fields. The Internet plays an important role in the area of human resource planning and development. 
Most planning and development organizations are now using computer technology and the Internet for staff recruitment. It should be noted that although the Internet has facilitated the process of job-seeking, it has not replaced the traditional methods, completely.

B. Importance of Job Portals

In the age of technology, the Internet has become the main source of information for jobseekers. Large corporations, institutions, and universities include information on career prospects on their websites. According to a survey, $70 \%$ of the workforce uses websites or portals on the Internet to search for jobs in France. These websites or portals provide a search engine to access information on job opportunities.

\section{IV.PROBLEM DEFINITION}

It is not possible for the every job seeker to view the newspaper daily and the result is many of the people are become unaware of the jobs. People have to visit different places for the jobs which is much time consuming and costly.

\section{SYSTEM ARCHITECTURE}

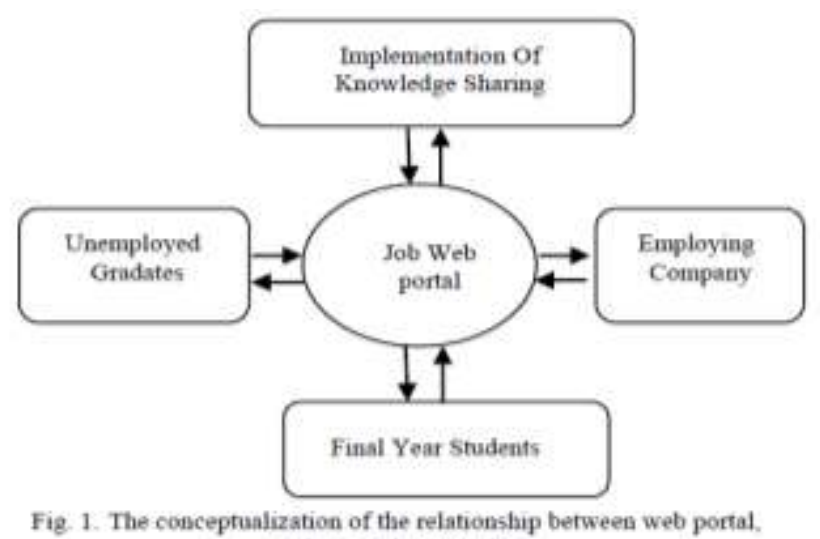
students and companies

\section{VI.HARDWARE AND SOFTWARE SPECIFICATION (MINIMUM REQUIREMENT)}

Database

Application Server

language

Browser

Operating System

Main Processor

Hard-disk Capaity

RAM
Sql server 2008

visual studio

Asp.Net

Internet Explorer 5.0

Window 2000,XP

Pentium IV

8 G.B

$256 \mathrm{MB}$

\section{SCREENSHOT}

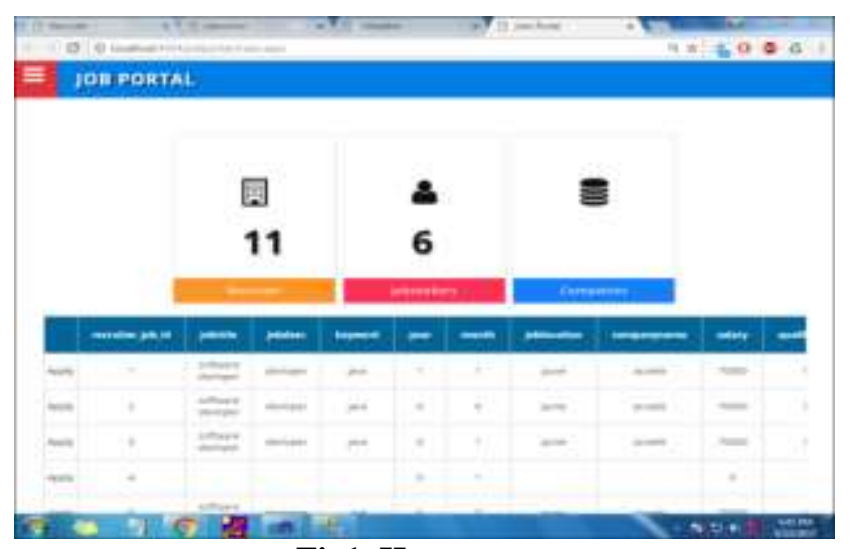

Fig1. Home page 


\section{Home Form:}

This is Home Form. In this Form show the how many recruiter, jobseeker and companies are registered. And Display the list for recruiter posted jobs. To display the job list for added by recruiter. Start for automatically counting for recruiter, jobseeker \& company.

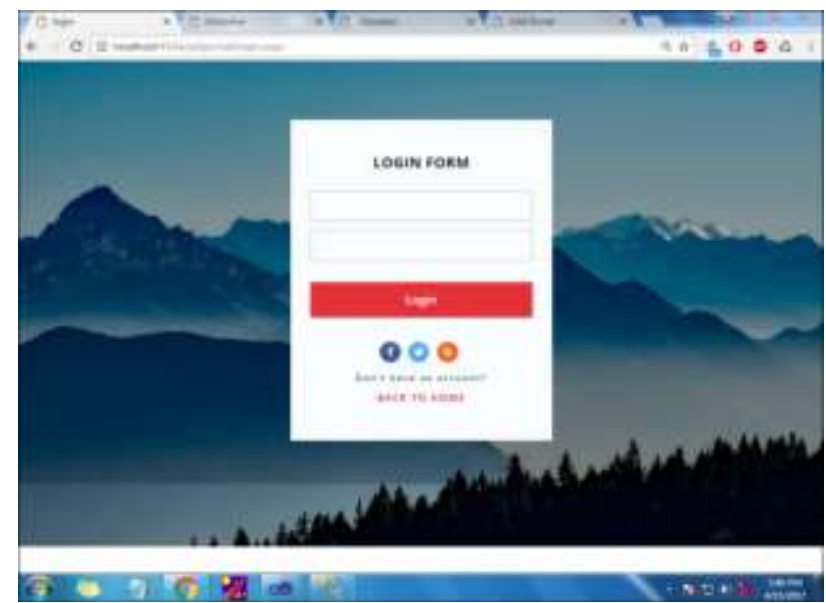

Fig2. Admin Login

\section{Admin Login:}

This admin log in Form. In this log in Form only uses for admin panel. To Enter Invalid User name and password system should be display the error message user name \& password should be invalid. Admin handle the whole system. Admin to check the details for recruiters \& job seekers. To add, Edit delete recruiter.

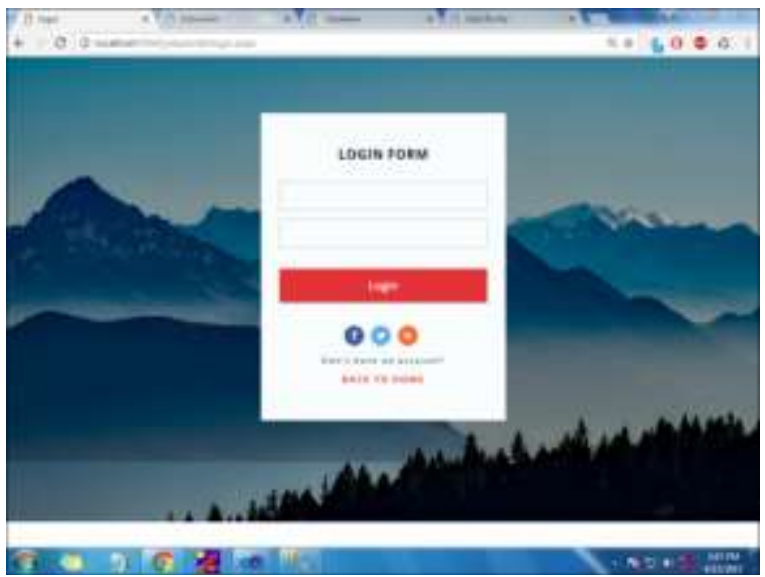

Fig3. Jobseeker Login.

Jobseeker Log in:

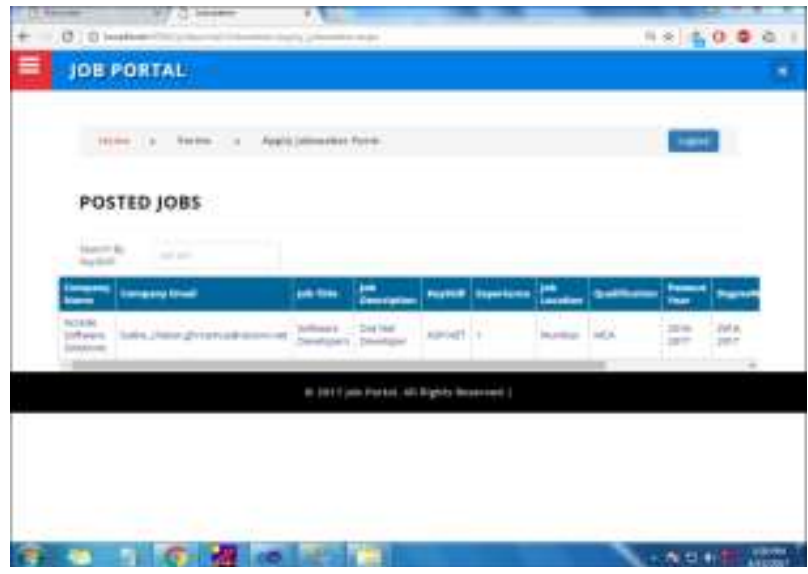

Fig4. Job seeker registration 
This is job seeker log in Form. You are already registered then directly log to the system otherwise first you are register then $\log$ in. Jobseekers enter invalid userid \& password system should be display Error message invalid username and password. This log in Form only use for job seeker To view the job for posted by the recruiter. And apply the jobs jobseeker.

\section{Job seeker registration:}

This is Job seeker registration Form. In this Form show job seeker registration form new job seeker's first registration then log in to the system. Jobseeker to fill a register forms all the data is correct format otherwise system should display error message. Then you are applicable for to apply job.

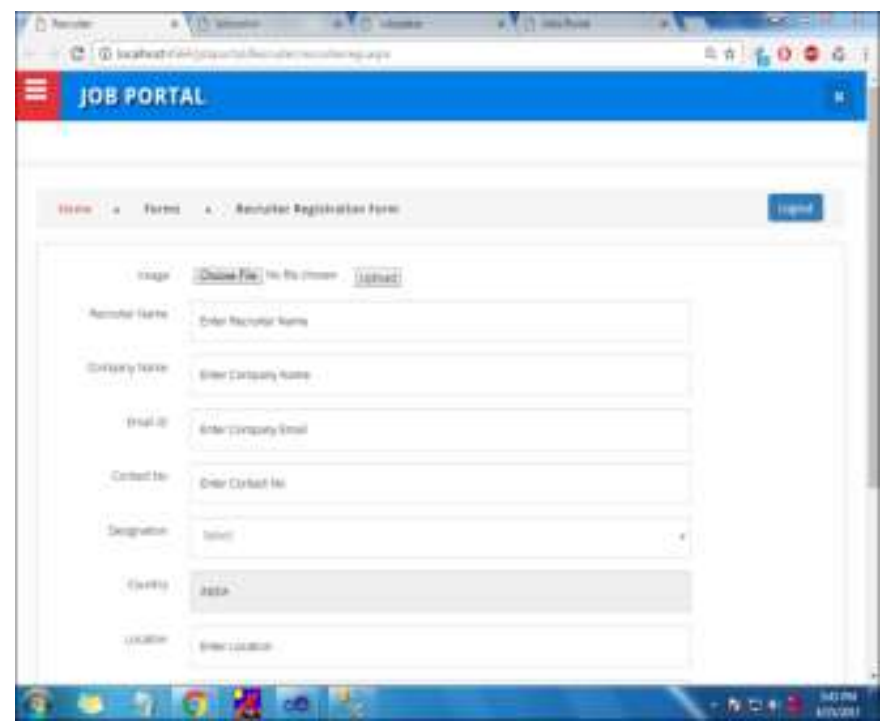

Fig5. Recruiter registration.

\section{Recruiter registration:}

This is recruiter registration Form. In this Form show recruiter registration form new recruiter first registration then $\log$ in to the system. recruiter to fill a register forms all the data is correct format otherwise system should display error message. Then you are applicable for to post to job.

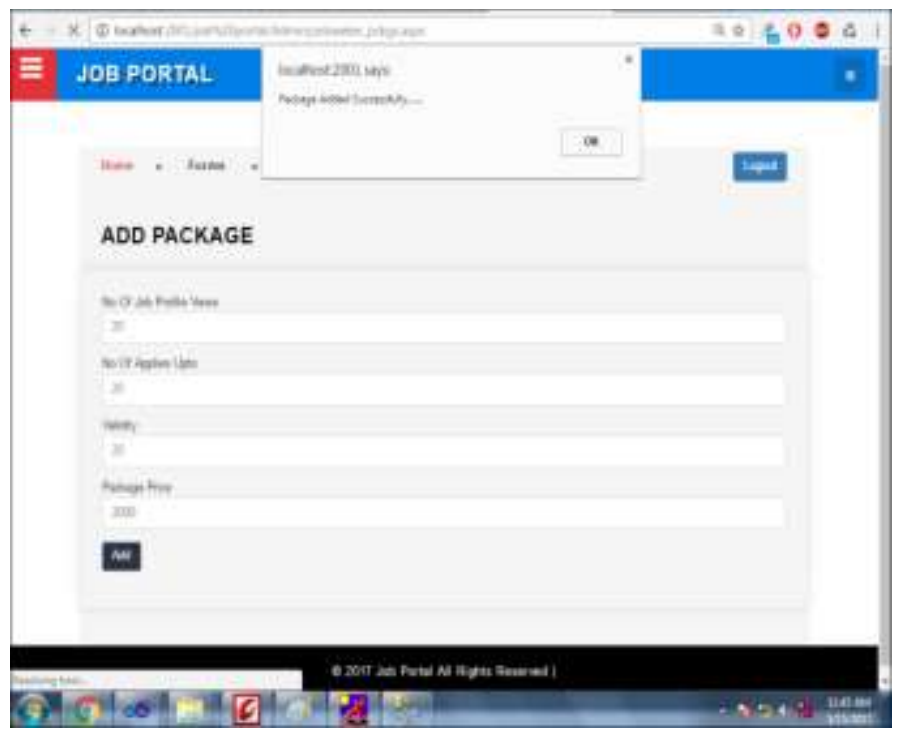

Fig6.Buy package for jobseeker

Buy package by job seeker:

This Form is buy package by jobseeker . Register candidate should be used this facility. To Enter invalid data to Buy a package system should be display Error message. To enter valid data to buy successfully package jobseeker. Then jobseeker applicable for next procedure. 


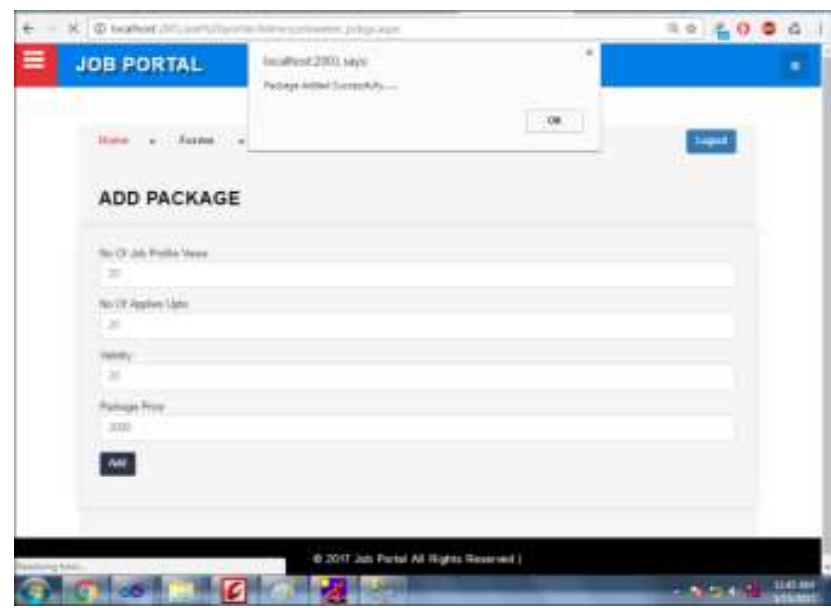

Fig 7.Recruiter add \& buy package

\section{Recruiter add \& buy package:}

This Form is add and buy package by recruiter. Add and buy package only used for recruiter panel. Recruiter to add and buy the packages for month or year wise and display to view the Admin and jobseekers. This packages is to buy the register jobseekers. Recruiter add package with valid data to show message to add package successfully other wise display error message.

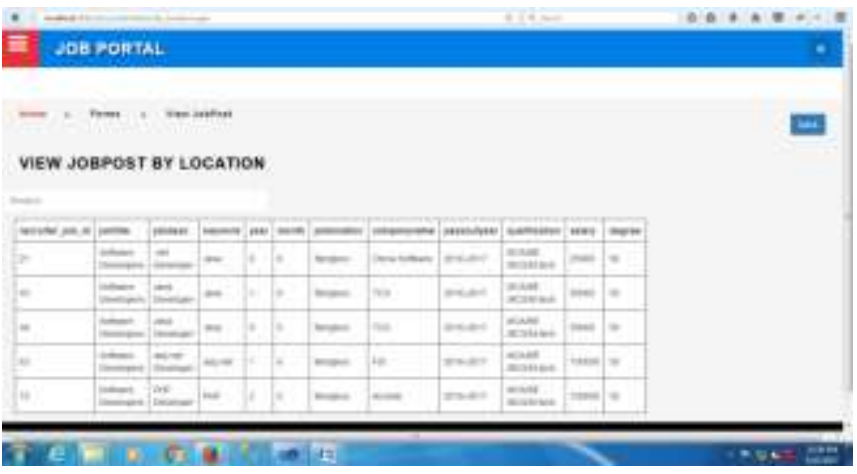

Fig8.Job post by location (admin)

Job post by location (admin):

This form is job post location wise by admin. This form only post job for admin and show to the registered recruiter and jobseeker admin to add or post job location wise. To search any location wise job is easily with company name, job title, location, salary jobseeker degree ect. To post job for the admin as well as recruiter.

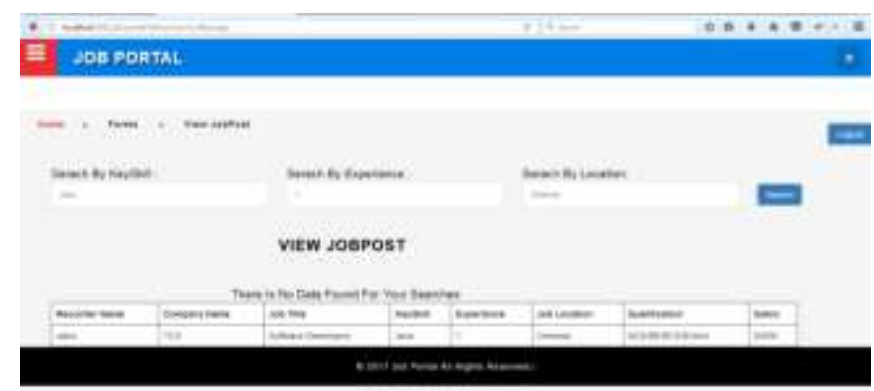

Fig9.Search Job

\section{Search Job:}

This form is search job. this form is used for the jobseekers. Jobseeker are search for job by location as well as experience and our skill to Enter all field s immediate matched job list display to the form with company name, location, experience ,key skill job title, salary etc. 


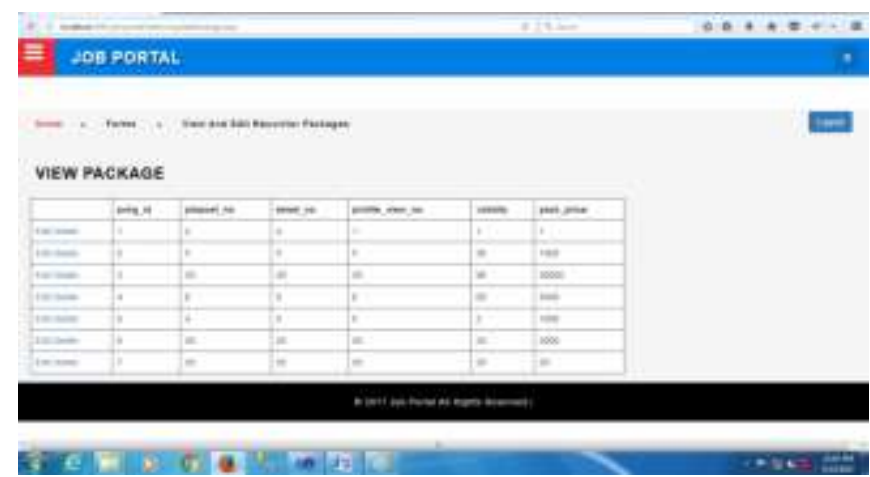

Fig10.Edit Delete package

Edit Delete package:

This Form is Edit and delete package. this form used for to edit in or Delete our package.You can any Edit our package system should be displayed it package successfully And delete any package to display delete package successfully . Easily recruiter and admin edit and delete packages.

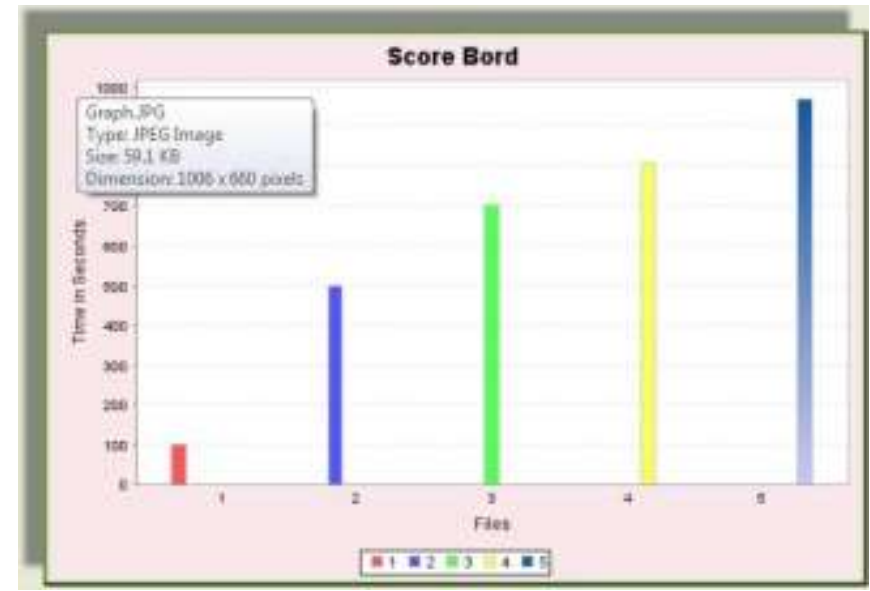

Fig11.Result graph

\section{Result Graph :}

This Form is Result graph . it is used for display the result for graph. How many job seeker are upload resume in day to day.

\section{ADVANTAGES}

1. Save time \& work load for TPC Staff and students.

2. Easy to access.

3. Avoid fake Entry.

4. Only Eligible students get chance.

5. Improve accuracy in result.

6. It will have a user friendly interface .

\section{APPLICATIONS}

The application can be used in educational domain where the data management of all users is important. The application area will be the centralized data storage of all users with efficient fine grained Updates.

\section{IX.CONCLUSION}

At last it can be concluded that the job portal system was a real learning experience. The principles of software production were well implemented throughout the system. The whole project undergoes with full of enthusiasm and with full of joyous moments. The project has been made as per as the given specifications. The system has been made 
as user friendly as possible by the use of HCIU principals. That is why management holds an important place in the software production.

Working on the project was really a learning experience and we have come a long way in building our concepts of software engineering. The "Job Portal System" developed by us is purely based on ASP .net platform. The overall purpose of this system is to computerized the whole process and thus prevent the intervening errors. We also tried to follow the holistic design principle so that the interface of the system is simple.

During the course of this assignment we have gone through many obstacles which made us to research and though increased our knowledge. After applying all the data modelling, object modelling and process modelling techniques now we are very well clear with all these concepts and fundamentals which will be going to help us in the future.

\section{ACKNOWLEDGMENT}

I express my thanks and full-hearted gratitude to my respected teacher, supervisor and guide of my project Proffer sir, Department of Computer Science and Engineering, Pune University, for his full guidance and entire support in completing this project successfully. I am very much thankful to him for the constant encouragement and continuous inspiration that he has given to me.

Finally I convey my real sense of gratitude and thankfulness to all my friends and family members for their unconditional support and encouragement during my project work without which I would hardly be capable of producing this huge work.

\section{REFERENCES}

[1] S. Bsiri, M. Geierhos, and C. Ringlstetter, "Structuring job search via local grammars," Advances in Natural Language Processing and Applications, pp. 201, 2008.

[2] M. Mansourvar and N. Y. Mohd, "Web portal as a knowledge management system in the universities," World Academy of Science, Engineering and Technology, vol. 70, pp. 968-974, 2010.

[3] J. Dorn and T. Naz, "Integration of Job portals by Meta-search," in Proc. 3rd International Conf. on Interoperability for Enterprise Software and Applications, Funchal, Portugal, 2007, pp. 401-412.

[4] M. Gangle, "The only way is up? Employment protection and job mobility among recent entrants to European labour markets," European Sociological Review, vol. 19, pp. 429, 2007

[5] N. Sulaiman and M. Burke, "A case analysis of knowledge sharing implementation and job searching in Malaysia," International Journal of Information Management, 2009

[6] E. Galanki, "The decision to recruit online: a descriptive study," Career Development International, vol. 7, pp. 243-251, 2002.

[7] S. Mauno, U. Kinnunen, and M. Ruokolainen, "Job demands and resources as antecedents of work engagement: A longitudinal study," Journal of Vocational Behavior, vol. 70, 2007, pp. 149-171.

[8] Doyle, Internet Your Way to a New Job: How to Really Find a Job Online, Happy about, 2008.

[9] ASP.NET 3.5 Unleashed, : by Stephen Walther

[10] Microsoft ASP.NET and AJAX: Architecting Web Applications, - by Dino Esposito

[11] ASP.Net With C\# by Shyam N. Chavda

[12] www.google.com

[13] www.w3school.com (it helps HTML, AJAX, JavaScript \& etc)

[14] www.asp.netpractice.com

[15] SQL Database

[16] http://www.Shubhevent.com/

[17] http://www.RajpathClub.com/

[18] http://www.sourcecode.com/ 